\title{
Estratégias de leitura aplicadas ao conto: uma proposta para a sala de aula
}

\author{
Renata Junqueira de Souza" \\ Gislene Aparecida da Silva Barbosa** \\ Elianeth Dias Kanthack Hernandes ${ }^{* * *}$
}

\section{Resumo}

Este artigo, sustentado na concepção de linguagem como forma ou processo de interação, considera que o ensino da leitura literária deva proporcionar condições para que o leitor dialogue com o texto, ativando conhecimentos prévios para realizar processos de inferência e construir sentidos para além do que está explícito. Leitores proficientes compreendem os textos por meio de recursos metacognitivos: fazem questões ao texto, relacionam ideias, identificam as informações essenciais etc. À escola cabe proporcionar aos estudantes condições de desenvolverem ou ampliarem a capacidade de compreender textos literários, especialmente o conto, que é um texto breve, narrativo, com tensão capaz de prender o leitor e que diz o máximo em poucas páginas. $\mathrm{O}$ objetivo do artigo é apresentar uma proposta de leitura para contos (para turmas de ensino fundamental - de $5^{\mathrm{o}}$ a $6^{\mathrm{o}}$ anos), com base nas Estratégias de Leitura, que são constituídas por sete procedimentos relacionados ao ato de ler: conhecimentos prévios; conexões; visualização; questionamento; inferência; sumarização e síntese.

Palavras-chave: Estratégias de Leitura. Contos. Literatura.

\footnotetext{
Doutora em Letras pela Universidade Estadual Paulista Júlio de Mesquita Filho (2000), livre-docente pela mesma Instituição (2012) no conjunto das disciplinas Conteúdos, Metodologia e Prática de Ensino de Língua Portuguesa I e II e Leitura, Literatura e Interpretação de Textos no Processo de Formação de Professores. É coordenadora do Centro de Estudos em Leitura e Literatura Infantil e Juvenil "Maria Betty Coelho Silva" na Unesp de Presidente Prudente, onde leciona na graduação e na pós-graduação em Educação. E-mail: recellij@gmail.com

** Doutora em Educação pela Universidade Estadual Paulista Júlio de Mesquita Filho (Unesp). Atualmente é professora da Universidade do Oeste Paulista (Unoeste) e diretora técnica do Núcleo Pedagógico da Diretoria de Ensino da Região de Presidente Prudente. E-mail: barbosagislene@gmail.com

**** Professora Assistente de Doutor da Universidade Estadual Paulista Júlio de Mesquita Filho - Unesp Campus de Marília - RDIDP- lotada no Departamento de Administração e Supervisão Escolar e Professora credenciada no Programa de Pós-Graduação em Educação - PPGE da FCT/Unesp/Presidente Prudente. Com Doutorado em Educação (2008) e Mestrado (2003), ambos realizados no Programa de Pós-Graduação em Educação da Universidade Estadual Paulista Júlio de Mesquita Filho - Marília e Pós-Doutorado em Educação realizado pelo PPGE/FCT/Unesp/Presidente Prudente. E-mail: netezeu@gmail.com
}

Data de submissão: dez. 2018 - Data de aceite: mar. 2019 http://dx.doi.org/10.5335/rdes.v15i1.8946 


\section{Introdução}

O desenvolvimento da capacidade de ler do aluno depende da interação que ele estabelece com o texto, do compartilhamento de significados, da mobilização de ações cognitivas na atribuição de sentido. Ler é uma ação social diretamente relacionada à compreensão dos aspectos linguísticos que formam o texto, mas também dos contextos sociais, históricos e culturais que nele se relacionam.

O sentido de um texto é construído na interação texto-sujeito e não algo que preexista a essa interação. A leitura é, pois, uma atividade interativa altamente complexa de produção de sentido, que se realiza evidentemente com base nos elementos linguísticos presentes na superfície textual e na sua forma de organização, mas requer a mobilização de um vasto conjunto de saberes no interior do evento comunicativo (KOCH; ELIAS, 2006, p. 11).

Ler, mais do que um simples ato mecânico de decifração de signos gráficos, é antes de tudo um ato de raciocínio, já que se trata de saber orientar uma série de raciocínios no sentido da construção de uma interpretação da mensagem escrita a partir da informação proporcionada pelo texto e pelos conhecimentos do leitor e, ao mesmo tempo, iniciar outra série de raciocínios para controlar o progresso dessa interpretação de tal forma que se possam detectar as possíveis incompreensões produzidas durante a leitura (COLOMER, 2002, p. 31-32).

Ler Literatura, além disso, é compreender a relação entre sentidos conotativos, reconhecendo as relações figuradas dos vocábulos e das situações propostas simbolicamente em cada gênero textual. Ler um romance ou ler um conto, por exemplo, envolve aspectos diferentes: enquanto no romance diversas ações, requintadas de detalhes, vão se desenrolando e se articulando para construir vários momentos de tensão até que ocorra um desfecho; no conto, costuma ocorrer apenas uma tensão que conduz o leitor a um alvo mais rápido e não menos elaborado que requer atenção ao uso exato de expressões e situações intimamente relacionadas ao conflito único proposto no enredo.

O gênero textual conto é um texto predominantemente narrativo, literário, breve, geralmente com poucos personagens, um narrador, tempo e espaço determinados. No conto, um conflito se constrói e, ao final, é resolvido. Para Gotlib (2006, p. 63), o conto é uma forma breve e nele não deve sobrar nada, é um texto enxuto. Na definição de Costa é importante contrapor o conto a outros textos narrativos:

Conto: assim como a novela e o romance são do tipo narrativo, assim também o conto literário o é. Em contraste com o romance, que geralmente é mais longo, o conto é mais curto, isto é, de configuração material narrativa pouco extensa, historicamente verificável. Essa característica de síntese traz outras: número reduzido de personagens ou tipos; esquema temporal e ambiental econômico, muitas vezes, restrito; uma ou poucas ações, concentrando os eventos e não permitindo intrigas secundárias como no romance ou na novela e uma unidade de técnica e de tom (fracção dramática, sedutora, em que tempo, espaço e personagem se fundem, muitas vezes) que o romance não mantém (2009, p. 75). 
Trabalhar com contos na escola básica é uma rica oportunidade de desenvolver o letramento dos alunos, já que a ação de contar histórias, de organizar sequências lógicas, de articular ideias etc. é necessária à vida cotidiana e precisa ser aprendida na escola. Além disso, e especialmente por isso, a Literatura tem a função de humanizar o leitor, dando a ele condições de dialogar com histórias que o levam à reflexão e à imaginação de outras experiências de vida e possibilidades. Ler textos informativos e não literários não assegura o desenvolvimento da compreensão dos textos artísticos, cuja linguagem, função social e organização não coincidem com textos como, por exemplo, as notícias ou os anúncios publicitários.

Ler é um conjunto de habilidades e comportamentos que se estendem desde simplesmente decodificar sílabas ou palavras até ler Grande Sertão: Veredas de Guimarães Rosa... uma pessoa pode ser capaz de ler um bilhete, ou uma história em quadrinhos, e não ser capaz de ler um romance, um editorial de jornal... Assim: ler é um conjunto de habilidades, comportamentos, conhecimentos que compõem um longo e complexo continuum (SOARES, 2002, p. 48).

Assim, o ensino da Literatura na escola implica a aprendizagem da compreensão leitora dos diferentes textos que compõem as produções da arte com as palavras. Muito mais que conhecer autores e estilos literários, é essencial ao aluno atribuir sentido ao que lê, numa relação dialógica com os textos. Ao longo da educação básica, os textos da esfera artística e literária são constituintes dos diversos currículos e materiais pedagógicos voltados ao ensino da língua materna no Brasil, no entanto, a presença dos textos literários na aula, por si só, não é garantia do desenvolvimento da aprendizagem de ler Literatura. É necessário transformar a leitura em um objeto de ensino.

Para ensinar a ler Literatura é imprescindível promover intervenções pedagógicas na aula para que o aluno aprenda a utilizar procedimentos que favoreçam a relação dialógica e sirvam como andaimes para que o sentido se construa (GERALDI, 2011). Aprender a compreender, interagindo com os textos, é um processo complexo que requer o desenvolvimento de "intimidade" entre o leitor e o texto. Essa pode ser conquistada pela ativação de conhecimentos que o leitor já possui e que é capaz de reconhecer no texto lido, articulando o já sabido ao elemento novo e (re)construindo sentidos. De acordo com Girotto e Souza (2010, p. 50) a compreensão de um texto não se dá apenas no final da leitura, mas também durante a leitura. $\mathrm{O}$ uso intencional das Estratégias de Leitura favorece o desenvolvimento da compreensão.

\section{Estratégias de Leitura aplicadas ao conto}

As Estratégias de Leitura são procedimentos que o leitor fluente usa para interagir com os diferentes gêneros textuais com o objetivo de compreen- 
dê-los. São ações cognitivas, feitas intencionalmente, após o estabelecimento de objetivos de leitura e mediante a ativação de conhecimentos prévios. Elas envolvem o estabelecimento de diálogos entre os saberes já construídos com os novos; a realização de imagens mentais; a construção de deduções; a relação entre ideias; a elaboração de sínteses etc.

Um leitor capaz de compreender os significados do texto realiza um complexo exercício cognitivo quando lê. Sua compreensão advém das paráfrases que realiza, motivadas pela projeção de imagens mentais conforme lê. Algumas vezes, as deduções são evolutivas, ou seja, o leitor as constrói gradativamente, enquanto aprofunda a leitura. Esse movimento do leitor é ativo, relaciona ideias do texto com seu conhecimento prévio, constrói imagens, provoca sumarizações, mobilizando várias estratégias de leitura. Assim, a atribuição consciente de significados ao texto faz parte do movimento de formar o leitor autônomo (GIROTTO; SOUZA, 2010, p. 51).

Girotto e Souza, amparadas em pesquisas norte-americanas (HARVEY; GOUDVIS, 2008), trouxeram para o Brasil reflexões e propuseram práticas de trabalho com o texto literário, nas quais as "estratégias de compreensão são meios para um fim e não um fim em si mesmo" (2010, p. 55). As referidas pesquisadoras brasileiras apresentam $7 E s$ tratégias de Leitura para a compreensão do texto: conhecimento prévio, conexões, visualização, inferência, questionamento, sumarização e sintese. Ainda destacam que todo ato de leitura precisa ter objetivo, uma vez que esse influenciará as decisões que o leitor tomará enquanto lê. O objetivo de leitura definirá quais procedimentos serão realizados e com qual finalidade.

Um bom leitor não mergulha num livro do começo ao fim sem antes saber o que quer do texto (aprender algo, recolher alguma informação, pesquisar algum tópico para o dever escolar, entre outras finalidades). $\mathrm{O}$ aluno folheia o livro lendo partes, essa atividade revela informações sobre o conteúdo, a estrutura da história, a localização dos elementos mais importantes e, principalmente, se o texto é pertinente diante dos objetivos do leitor (GIROTTO; SOUZA, 2010, p. 50).

Com a intenção de exemplificar uma aula de leitura literária para o $5^{\mathrm{o}}$ ou $6^{\mathrm{o}}$ ano do ensino fundamental, sugerimos o conto de Ricardo Azevedo "As aventuras de João Grilo", pois o enredo (com um personagem esperto e cheio de estratégias para se sair bem em todas as situações) costuma agradar aos alunos nessa faixa etária - conto de adivinhação.

O conto em questão apresenta a história de João Grilo, descrito pelo narrador como "cabra safado" que passava o dia deitado na rede e que não gostava de trabalhar. Um belo dia, João Grilo resolveu ser adivinho e saiu pelo mundo. Em uma cidade, escondeu três burros no mato e, quando o dono sentiu falta dos bichos, João fez uma adivinhação falsa, levou todos ao encontro dos animais e os enganou.

Por conta disso, o rei daquele lugar mandou chamar João para adivinhar quem roubou as joias da rainha. Se ele não adivinhasse em três dias, iria para a forca. João Grilo sabia que iria morrer, por isso pediu para ficar os três dias no palácio onde comeria e beberia "do bom 
e do melhor". Ao final do primeiro dia, quando um empregado veio retirar a comida, João falou bem alto que o primeiro já tinha passado. Ele estava falando do fim do dia, mas o empregado, que era um dos ladrões, pensou que ele falava sobre o roubo. No segundo dia, com o outro empregado ladrão, aconteceu a mesma coisa. No terceiro dia, o terceiro empregado ladrão ficou com medo, confessou tudo e entregou as joias. $\mathrm{O}$ rei ficou feliz, porém deu mais um teste para 0 adivinho: foi até a cozinha, pegou o rabo de uma porca e perguntou para João o que estava escondendo na mão. João, assustado, falou: "agora é que a porca torceu o rabo". O rei viu que João acertou de novo, por isso deu ao adivinho ouro e muito dinheiro.

Em outra cidade, João Grilo ficou sabendo que outro rei daria a filha muito bonita em casamento para quem respondesse quatro perguntas. Foi até o palácio e se apresentou como João Baratão. O rei avisou que se João não respondesse às quatro perguntas, iria direto para o cemitério. As três perguntas iniciais eram: 1. Qual é o peso da Terra? 2. Quanta água existe no mar? 3. Quantas estrelas existem no céu? João deu respostas tão malucas quanto as perguntas do rei e o rei gostou de todas. Na pergunta final, o rei disse: "o que é que eu estou pensando agora?”. João Grilo respondeu: "Está pensando que eu sou João Baratão, mas eu sou João Grilo!". Todos riram. O rei aprovou a resposta. A princesa gostou dele. A festa de casamento durou sete dias e os pais de João foram convidados.
A seguir apresentaremos as Estratégias de Leitura e, em seguida, sugestões de como aplicá-las ao texto de Ricardo Azevedo.

Diante dos objetivos de leitura, o leitor ativa seus conhecimentos prévios relacionados ao texto que lerá. Essa é, segundo Santos e Souza, "a base para outras estratégias de leitura, porque o leitor não consegue entender o que está lendo sem pensar naquilo que já conhece" (2011, p. 30). Podemos dizer que o conhecimento prévio é considerado, na abordagem teórica sobre a qual discorremos, elemento primordial da construção do sentido. Nessa esfera de reflexão, Girotto e Souza assinalam que:
Antes de ler, bons leitores geralmente ativam conhecimentos prévios que podem então ser relacionados às ideias do texto. O exercício de ativar essas informações interfere, diretamente, na compreensão durante a leitura. Folhear o livro passando rapidamente os olhos pela narrativa na pré- -leitura, geralmente, resulta na formulação de hipóteses baseadas no conhecimento pré- vio do leitor sobre o que trata e como trata a história (2010, p. 50).

Girotto e Souza (2010) valorizam a ativação de conhecimento prévio e a realização de previsões sobre a história e a criação de perguntas para o texto, porém as últimas autoras avançam no sentido de oferecer propostas para a atuação em sala de aula, caso os alunos não tenham desenvolvido autonomia e fluência na leitura. Para uma ação com o conhecimento prévio, Santos e Souza (2011, p. 66) destacam a realização de perguntas: "o que eu já sei sobre a história a ser 
lida?" e "o que eu quero saber sobre o que irei ler?", pois é isso que leitores fluentes fazem quando iniciam uma atividade de leitura. Dessa maneira,

Os leitores vão além do sentido literal da história ou texto. Um leitor que entende pode perceber a mensagem em uma história folclórica, formar uma nova opinião de um editorial, desenvolver um entendimento mais profundo de problemas quando ler um artigo. Adquirir informação nos permite ganhar conhecimento sobre o mundo e nossa relação com ele. Nós edificamos nosso armazém de conhecimentos não para o seu próprio bem, mas para desenvolver o insight (compreensão/solução). Com o insight, nós pensamos mais profundamente e criticamente. Nós indagamos, interpretamos e avaliamos o que lemos (HARVEY; GOUDVIS, 2008, p. 9, tradução nossa).

Atividades antes da leitura do conto "As aventuras de João Grilo" - ativação do conhecimento prévio:

Embora o conhecimento prévio precise ser ativado ao longo de toda a leitura, é essencial que antes de os alunos lerem com o professor o conto indicado, haja uma atividade prévia que permita a eles construírem hipóteses sobre a história que será lida. Ao pensar no possível enredo para a narrativa ou ao imaginarem características para um personagem, os alunos buscam em seus saberes uma rede de significação, a qual colaborará no diálogo leitor-texto.

Uma das maneiras de ativar o conhecimento prévio consiste na utilização do título do conto "As aventuras de João Grilo" e de uma das ilustrações presente no livro, na qual o personagem João Grilo aparece bem faceiro trajado de terno azul, chapéu marrom, uma florzinha verde na mão em um cenário composto por vários elementos da natureza como pássaros, borboleta e árvore.

O professor dirá à turma que todos farão juntos a leitura de um conto intitulado "As aventuras de João Grilo", em seguida mostrará a ilustração e fará perguntas aos alunos como: o que vocês esperam encontrar em um conto com este título? Observando a ilustração, quem é esse personagem? Quais são as características físicas e psicológicas dele? Quais aventuras ele viverá? Como vocês chegaram a essas conclusões? Em que vocês se basearam?

As perguntas anteriormente elencadas exemplificam possibilidades para que os alunos comecem a pensar no texto que será lido, ou seja, deem respostas lógicas, sustentadas em pistas dos elementos linguísticos e não linguísticos apresentados, ativando, portanto, seu conhecimento prévio. É importante que o professor anote na lousa as diferentes respostas dos alunos, sem a pretensão de avaliar respostas "certas ou erradas" da turma, porque a manifestação oral do aluno indicará que atividades mentais estão acontecendo na tentativa de construção dos sentidos.

Outra possibilidade ativar o conhecimento prévio encontra-se na utilização de palavras que representem objetos importantes que aparecem no enredo como: burros, joias, estrelas. O professor pode apresentar o título do conto e dizer aos alunos que os três objetos (mencionados anteriormente) aparecerão na história 
e, assim, perguntar aos alunos como eles acham que tais objetos aparecerão na história ou estarão relacionados ao personagem principal.

Uma segunda estratégia é a conexão, a qual consiste em o leitor estabelecer relações entre o texto lido e suas experiências de vida. As conexões podem ser de três tipos: conexão texto-leitor; conexão texto-texto; conexão texto-mundo. As conexões texto-leitor acontecem quando alguma informação ou trecho do texto lido faz o leitor se lembrar de algo que ele viveu. As conexões texto-texto ocorrem quando o leitor reconhece, no texto que está lendo, semelhanças (temáticas, estruturais ou de situações/enredo/personagens) com algum outro texto já lido. As conexões texto-mundo se manifestam quando o leitor identifica semelhanças entre o texto que é lido e acontecimentos da sociedade, um acontecimento mais global. Sobre esse estabelecimento de conexões, Girotto e Souza completam:

Fazer conexões com as experiências pessoais facilita o entendimento. As vivências e conhecimentos prévios dos leitores abastecem as conexões que fazem. Livros, discussões, boletins de notícias, revistas, internet e até mesmo as conversas informais criam conexões que levam a novos insights. Ensinar as crianças a ativar seus conhecimentos prévios, bem como seus conhecimentos textuais, e pensar sobre suas conexões é fundamental para compreensão (2010, p. 67).

Mediante a leitura, estabelece-se uma relação entre leitor e autor que tem sido definida como de responsabilidade mútua, pois ambos têm a zelar para que os pontos de contato sejam mantidos, apesar das divergências possíveis em opiniões e objetivos (KLEIMAN, 2013, p. 71).
Leitores fluentes fazem conexões mentalmente, como se conversassem com o texto que está sendo lido. Quando os alunos não conseguem fazer isso "naturalmente", são possíveis intervenções em sala de aula, Girotto e Souza sugerem a utilização de uma "folha do pensar" (2010, p. 71-74), na qual o leitor poderá anotar as conexões que fez durante a leitura do texto.

Uma terceira estratégia é a visuali$z a c ̧ \tilde{a} o$, que tem como objetivo central a criação de imagens mentais pelo leitor. Quando o leitor imagina o que está lendo, está ativando seus conhecimentos prévios e criando a história em sua mente, atribuindo a ela um sentido. Leitores que visualizam, enquanto leem, conseguem lembrar mais o texto lido. Girotto e Souza apontam que: "Quando os leitores visualizam, elaboram significados ao criar imagens mentais, porque criam cenários e figuras em suas mentes enquanto leem, fazendo com que se eleve o nível de interesse e a atenção seja mantida" (2010, p. 85).

De acordo com Cosson, "uma forma de visualizar é verificar no texto palavras e expressões que remetem aos sentidos ou como as descrições são transformadas em imagens pelo leitor" (2014, p. 117).

Uma quarta estratégia é a inferência, que significa chegar a uma conclusão lógica a partir de pistas que estão no texto: "O leitor, ao inferir, ultrapassa o sentido literal do que está lendo e encontra o que não está explícito, compreendendo o implícito, as entrelinhas do texto" 
(SANTOS; SOUZA, 2011, p. 32). Uma das possibilidades de utilização da inferência consiste em construir o sentido de um vocábulo a partir da análise do seu contexto de utilização. Também sugestão das autoras é fazer inferência a partir de imagens disponíveis em diferentes gêneros textuais.

Leitores inferem quando utilizam o que já sabem, seus conhecimentos prévios e estabelecem relações com as dicas do texto para chegar a uma conclusão, tentar adivinhar um tema, deduzir um resultado, chegar a uma grande ideia etc. Se os leitores não inferem, então não entendem a essência do texto que leem. Às vezes, as perguntas do leitor só são respondidas por meio de uma inferência. Quanto mais informações os leitores adquirem, mais sensata a inferência que fazem (GIROTTO; SOUZA, 2010, p. 76).

Outra estratégia é a do questionamento ou perguntas ao texto. Ela consiste na relação que o leitor estabelece com o texto durante a leitura, fazendo perguntas que ajudam a entender a história:

As perguntas são o coração do ensino e da aprendizagem. Os seres humanos são levados a dar sentido ao seu mundo. Perguntas abrem as portas para a compreensão [...]. Questionar é a estratégia que impulsiona os leitores para a frente. Quando os leitores têm perguntas, eles são menos propensos a abandonar o texto. Os leitores proficientes fazem perguntas antes, durante e depois de ler. Eles questionam o conteúdo, o autor, os eventos, as questões e as ideias no texto (HARVEY; GOUDVIS, 2008, p. 22, tradução nossa).

As perguntas são criadas e usadas pelo leitor experiente no processo de construção do sentido. Quando o leitor não vai fazendo questões ao texto, corre-se o risco de a interação não ocorrer e de a compreensão não se efetivar. Considerando o professor como mediador de leitura, cabe a ele mostrar aos alunos, enquanto lê o texto, exemplos de perguntas para entender/construir o sentido.

A estratégia questionamento ou perguntas ao texto também pode ser utilizada no momento depois da leitura, dando a oportunidade de ampliação da compreensão do estudante.

Bons leitores estão sempre lendo em voz alta e fazendo perguntas ao material de leitura, uma ação que pode ajudar a explicar alguns aspectos confusos da narrativa, a encontrar respostas, a solucionar problemas e a localizar informações específicas no texto. A estratégia de fazer perguntas ao escrito ainda induz o leitor à pesquisa (SANTOS; SOUZA, 2011, p. 33).

Atividades durante a leitura do conto "As aventuras de João Grilo"-visualização, conexões, questionamentos $\mathrm{e}$ inferências:

A leitura propriamente dita pode ser feita em voz alta pelo professor que intencionalmente fará paradas pontuais a fim de aplicar as Estratégias de Leitura. O ideal é que cada aluno tenha um exemplar do livro para ler com o professor.

Para aplicar a estratégia de visualização e favorecer a construção de imagens mentais no aluno, o professor pode ler o início da história quando o João Grilo parou na cidade e simulou adivinhar onde estavam os burros supostamente perdidos. Nesse momento, o docente pode solicitar aos alunos que ilustrem em uma folha essa parte da história e depois mostrem aos amigos como imaginaram a cena. Esta atividade pode ser construída 
em quadrinhos, para assegurar a progressão temporal, mostrando as ações do personagem ao longo do tempo.

Depois, o professor continua a ler o texto com os alunos e na parte da história em que João Grilo estava por três dias num quarto confortável com muita comida e bebida na tentativa de solucionar o mistério do roubo das joias preciosas da rainha, o docente pode aplicar a estratégia de conexão, perguntando aos alunos se algum deles já leu uma história parecida, ou já viveu uma história semelhante ou conhece alguém que goste de adivinhação. Nesse momento, o professor pode ilustrar com conexões que ele mesmo fez (é possível citar as histórias literárias de Pedro Malasartes ou mencionar histórias dos filmes de Mazzaropi). O importante é deixar evidente para o aluno que as conexões ajudam a entender o texto que está sendo lido, já que articula o que está no texto ao que o leitor conhece, portanto todos os links precisam ser justificados/ancorados em palavras ou expressões do texto, ou seja, "quando li o parágrafo tal, lembrei-me da história $x$ pelo seguinte motivo...".

Dando prosseguimento à leitura, o professor pode realizar perguntas para os alunos que os ajudem no estabelecimento de relações entre as partes do texto ou na compreensão do sentido de uma frase. Por exemplo, na parte final do texto, quando João Grilo é questionado pelo segundo rei a respeito do peso da Terra, João respondeu: "Mande tirar todas as pedras e árvores do mundo que eu peso a terra e depois digo"; tal frase não é explicada pelo narrador, mas precisa ser compreendida pelo leitor como uma esperteza do personagem que ao pedir algo impossível para o rei (retirada das pedras e árvores) estava respondendo ao monarca na mesma moeda, ou seja, pedindo algo ilógico para se safar da obrigação de uma resposta convencional. Por isso, perguntar aos alunos qual era a intenção de João Grilo ao dar essa resposta ao rei é um exemplo de como a estratégia de questionamento pode ser usada. Além disso, uma pergunta articuladora para questionamento pode ser feita aos alunos quanto às artimanhas de adivinhação usadas por João Grilo, isso faria com que o aluno retomasse cada resposta sagaz do personagem ao longo da história.

A estratégia de inferência pode ser articulada à estratégia de questionamento, porque por meio de perguntas o professor pode favorecer nos alunos o desenvolvimento de deduções lógicas. Um exemplo disso está na concessão que o segundo rei deu a João Grilo para se casar com a princesa. Uma possível pergunta é: "Por que o segundo rei gostou de João de Grilo ao ponto de lhe conceder a mão da princesa?"; a resposta a esta pergunta requer um processo inferencial, que mostra o quanto o segundo rei gostava de adivinhação e era parecido com o João Grilo (cheio de espertezas e estratégias para enganar os outros com as palavras).

Outras questões com inferências, questionamentos, visualizações e cone- 
xões podem ser feitas ao longo do texto. Os exemplos anteriormente citados não esgotam as possibilidades de diálogo com o conto.

Uma sexta estratégia é a sumarização, que consiste na identificação das partes ou ideias mais relevantes do texto. Quando o leitor compreende a estrutura do texto, ele consegue identificar as partes essenciais do que leu. Portanto, ter domínio dos elementos da narrativa ou da estrutura do parágrafo em textos informativos, por exemplo, ajuda a priorizar o que é mais importante em cada texto. As autoras sugerem $o$ trabalho com o grifo, o uso de anotações às margens do texto ou o uso de blocos de notas para parafrasear a informação.

Sumarizar é aprender a determinar a importância, é buscar a essência do texto. Preferimos pensar que os dias de sublinhar e checar a ideia principal acabaram. Infelizmente, exercícios de compreensão e questões nas provas ainda exigem que os leitores escolham uma ideia principal [...], aquilo que determinamos ser importante em um texto depende de nosso propósito em lê-lo. Quando o leitor lê ficção, está focado nas ações das personagens, motivos e problemas que contribuem para o tema (GIROTTO; SOUZA, 2010, p. 93).

A última estratégia é a síntese, a qual está intimamente relacionada a um processo de produção textual, uma vez que sintetizar consiste em apresentar um resumo do texto acrescido de uma visão pessoal. Na sintese, o leitor autônomo manifesta sua apreciação acerca do texto, tem a oportunidade de explicitar o seu pensamento:
Os leitores, ao sintetizarem a informação, enxergam uma figura maior, eles não estão simplesmente se lembrando dos fatos ou repetindo-os. Antes, acrescentam a nova informação aos conhecimentos já existentes. Algumas vezes, adicionam novas informações para o aprimoramento do conhecimento prévio, desenvolvendo o pensar e aprendendo mais durante o processo. Outras vezes, mudam o seu pensar baseado em suas leituras, ganhando uma perspectiva inteiramente nova, por isso, quando sintetizam, as crianças alcançam um entendimento mais completo do texto (GIROTTO; SOUZA, 2010, p. 103).

Nessa linha, Harvey e Goudvis consideram que:

À medida que os leitores se movem através do texto, seu pensamento evolui. Eles acrescentam novas informações ao que já sabem e constroem o significado à medida que seguem a leitura. Sintetizar requer dos leitores a triagem através de grandes quantidades de informações para extrair ideias essenciais e combiná-las para formar uma imagem geral do que foi lido, para obter o essencial. Como os leitores destilam texto em algumas ideias importantes ou conceitos maiores, eles podem formar uma perspectiva particular que leva a uma nova visão. Sintetizar é a estratégia que permite aos leitores mudar seu pensamento (2008, p. 25 , tradução nossa).

Atividades depois da leitura do conto "As aventuras de João Grilo" - sumarização e síntese:

Depois da primeira leitura completa do texto ter sido realizada, é importante criar oportunidades de releitura com os alunos, pois a retomada do texto permite a ampliação dos sentidos. Dessa forma, a estratégia de sumarização pode ser aplicada tanto para que os alunos grifem as partes principais do texto quanto para 
que completem um gráfico organizador (uma tabela com as palavras ou expressões que resgatam as ideias-chave do texto). Uma possível abordagem para a sumarização é pedir que os alunos encontrem os três atos da narrativa: situação inicial, conflito e resolução. Eles podem grifar com cores diferentes cada um desses atos, assim, terão oportunidade de refletir sobre a estrutura padrão de um texto narrativo.

Depois de sumarizar, os alunos podem reescrever a história lida. Essa é a aplicação da estratégia sintese, a partir da qual o leitor reorganiza a história com sua própria linguagem e faz escolhas semânticas e sintáticas que evidenciam o seu domínio linguístico e a compreensão da história. Os alunos podem escrever a mesma história, mas darão a ela marcas da subjetividade de cada leitor. A pedido do professor, eles podem criar um final surpreendente e, na hora da socialização dos textos escritos pela turma, cada aluno poderá justificar sua escolha e criação.

\section{Considerações finais}

As Estratégias de Leitura ajudam no desenvolvimento de aulas com o conto, visto que favorecem o diálogo entre $o$ leitor e o texto, relacionando os aspectos linguísticos aos saberes dos alunos, por isso elas são relevantes para a sustentação de propostas de aulas de leitura literária que contemplem o trabalho com a compreensão textual.
A organização da aula de leitura literária com o conto pode ser constituída por três momentos: antes da leitura, durante a leitura e depois da leitura, sendo que, respectivamente em cada etapa podem ser trabalhadas as seguintes estratégias pelo professor, na situação de leitura em voz alta: conhecimento prévio; visualização, inferências, questionamento, conexões; sumarização e síntese.

A proposta aqui explicitada é apenas uma sugestão para uma aula de leitura e não tem caráter prescritivo, haja vista a possibilidade diversa de utilização das Estratégias de Leitura em textos literários.

\section{Reading Strategies applied to the short story: a proposal for the classroom}

\section{Abstract}

This article, based on the conception of language as a form or process of interaction, considers that the teaching of literary reading should provide conditions for the reader to dialogue with the text, activating previous knowledge to carry out inference processes and construct meanings beyond what is explicit. Proficient readers understand texts through metacognitive resources: they make questions to the text, relate ideas, identify essential information, and so on. It is the school's job to provide students with the ability to develop or expand literacy skills, especially the story, which is a brief, narrative text with tense power to trap the reader and say the most in a few pages. The 
purpose of this article is to present a reading proposal for short stories (for grades of elementary school 5 th to 6th grade), based on Reading Strategies, which are constituted by seven procedures related to reading: previous knowledge; connections; visualization; questioning; inference; summarization and synthesis.

Keywords: Reading Strategies. Short Stories. Literature.

\section{Referências}

AZEVEDO, Ricardo. As aventuras de João Grilo. In: . Contos de adivinhação: versões de contos populares. São Paulo: Ática, 2008. p. 63-69.

COLOMER, Teresa; CAMPS, Anna. Ensinar a ler, ensinar a compreender. Porto Alegre: Artmed, 2002.

COSSON, Rildo. Círculos de leitura e letramento literário. São Paulo: Contexto, 2014.

COSTA, Sérgio Roberto. Dicionário de gêneros textuais. 2. ed. Belo Horizonte: Autêntica, 2009.

GERALDI, João Wanderley. Unidades básicas do ensino de Português. In: (Org.).

O texto na sala de aula. 5. ed. São Paulo: Ática, 2011. p. 59-79.

GIROTTO, Cyntia Graziella Guizelim Simões; SOUZA, Renata Junqueira de. Estratégias de leitura: para ensinar alunos a compreender o que leem. In: SOUZA, Renata Junqueira et al. (Org.). Ler e compreender: estratégias de leitura. Campinas: Mercado de Letras, 2010. p. 45-114.

GOTLIB, Nádia Battella. Teoria do conto. 11. ed. São Paulo: Ática, 2006.
HARVEY, Stephanie; GOUDVIS, Anne. Strategies that work: teaching comprehension to enhance understanding. Portland: Stenhouse Publishers \& Pembroke Publishers, 2008.

KLEIMAN, Angela. Texto e leitor: aspectos cognitivos da leitura. 15. ed. Campinas: Pontes, 2013.

$\mathrm{KOCH}$, Ingedore Villaça; ELIAS, Vanda Maria. Ler e compreender: os sentidos do texto. São Paulo: Contexto, 2006.

SANTOS, Ana Maria Martins da Costa; SOUZA, Renata Junqueira de. Andersen e as estratégias de leitura. Campinas: Mercado de Letras, 2011.

SOARES, Magda. Letramento: um tema em três gêneros. Belo Horizonte: Autêntica, 2002. 